\title{
STRATEGY FOR AGRICULTURAL DEVELOPMENT IN CITY OF ZANJAN, IRAN: APPLICATION OF SWOT-AHP METHOD
}

\author{
Mostafa Nazari Nasab \\ Department of agricultural mechanization \\ Science and Research Branch, Islamic Azad University \\ Tehran, Iran \\ E-mail: nazarinasab.m@srbiau.ac.ir \\ Majid Azizi \\ Department of Wood \& Paper Sciences and Technology \\ University of Tehran \\ Karaj, Iran \\ E-mail: mazizi@ut.ac.ir
}

\begin{abstract}
Decision making and strategy selection to agricultural development in underdeveloped and developing countries is always like as major model which can be get on the capital of their country. In these countries Strategy selection is regardless to the characteristics of different regions, there is similar problem in Iran. This research was part of major study that wants to analysis agricultural development of Zanjan province in Iran by using system analysis methods. Zanjan province is in northwestem of Iran, Which has seven cities (Zanjan, Abhar, Eijroud, Tarom, Mahneshan, Khodabande, and Khoramdare). City of Zanjan is center of Zanjan province. This city is pole of onion and rice production in Zanjan province. By use SWOT (Strengths, Weaknesses, Opportunities and Threats) analysis for agricultural mechanization of Zanjan province, we found four factors which used as altematives in AHP method. Hierarchy model of this research has goal, criteria and altematives. Goal is goal is recognize important and Effective SWOT factor of agricultural development in city of Zanjan. Criteria are management and planning, techniques and Economics that were the most important criteria for statistical communities. Altematives are SWOT factor. Results of pair compressions showed techniques is the most important criteria in Zanjan and Economics and management and planning are the second and third criteria in this city so use these criteria in the AHP model. Local weights were calculated for criteria and altematives and then overall weights were calculated for only altematives. Results showed ST strategy is more important strategy in the city of Zanjan. One of the ST strategies is "Use the sample agricultural

."machines with minimum purchase price
\end{abstract}

Keywords: AHP method, SWOT analysis, AHP-SWOT hybrid method, strategy, .agricultural mechanization 


\section{Introduction .1}

These days a lot of energy is consuming to do agricultural operation and mechanization of agriculture. Development criteria such as energy ration and energy efficiency have special politics which necessary in: waste prevention, estimation of needs, optimum consumption, and education in case of accurate use of energy and... . Energy using of farm machinery consist three parts, energy consumption before entering to farm for example manufacturing step, energy consumption inside the farm for example tillage and planting, energy consumption outside of farm for example transportation. we can optimize energy consumption by taking strategies in every three parts. in Iran agricultural development activities done without consideration of specific conditions of various region and decision making done similar for all of them. Distribution of agricultural machinery is not effective on agricultural development because entering the machine into fam without recognizing it increases the risks, for .example investment risk, soil erosion, product reduction and timeline costs

In this study, we attempt to assess the effect of different conditions to rate the cities of Zanjan province regard to agricultural development perspective. We use the strengths, weaknesses, opportunities, and threats (SWOT) approach in combination with analytic hierarchy process (AHP) to achieve this issue. The SWOT-AHP allows us to classify the cities in the hierarchical structure, evaluate factors in the pair compressions and quantify the relative importance of criteria in order to rate the SWOT factors. We utilize preference data involved agricultural mechanization usage in Zanjan province. Although SWOT-AHP is a Common method in strategic planning literature but it is the first time that someone applied it in Iranian agriculture. Our wish is to bring the system analysis .methods in the Iranian agriculture for improve the decision making process

\section{Literature Review .2}

Reviewing the literature of SWOT analysis or AHP technique reveals that the joining of these two methods is a quite novel approach, and there are only a

:few papers conceming this methodology Kurttila in his study whit subject utilizing the analytic hierarchy process (AHP) in SWOT analysis - a hybrid method and its application to a forest .certification case, they used AHP for rating of SWOT factors Yuksel and Dagdeviren in their study, researched on the using the analytical network process (ANP) in SWOT analysis, their study results showed SWOT analysis cannot determine important of factors analytical network process .can do it and ANP can complete SWOT analysis 
Shrestha in his study, researched on the exploring the potential for silvopasture adoption in south-central Florida: an application of SWOT-AHP method, they plus weight of each of SWOT factors then results showed various .regions has different conditions

Zaerpour in his study, researched on the Make to order or make to stock decision by a novel hybrid approach, they examination some hybrid method that one of them was SWOT-AHP method. Their study showed use hybrid method can give us correct answer and it better than use one of the methods as single

.(Zaerpour et al., 2008

\section{Hypotheses/Objectives .3}

\section{:Hypotheses}

Different factors are effective on the development of agricultural .1 mechanization in city of Zanjan

.Different factors have different important in city of Zanjan $\mathbf{. 2}$

AHP-SWOT hybrid method can help us to achieve accurate strategic $\mathbf{. 3}$

.planning

\section{:Objectives}

.Rank the SWOT factors of Zanjan based on important criteria .1 SWOT analysis of agricultural mechanization and use these results as .2 .altematives on the AHP structure in city of Zanjan

Select the best and suitable strategy to development of agricultural .3 .mechanization in city of Zanjan

\section{Research Design/Methodology .4}

This method includes several steps. First we use some indexes to determine statistical community. 2nd we calculate sample size of statistical community. 3rd we use SWOT analysis for detemine strengths, weaknesses, opportunities and threats of agriculture then select three important case for every factors between SWOT analysis result. $4^{\text {th }}$ we found three important criteria. 5th we form hierarchy which the goal is in upstairs of this hierarchy then criteria is in middle of hierarchy and alternatives is in the bottom. We used Daier and Forman theory to form hierarchy. They suggested hierarchy can form as this structure: goal, criteria and alternatives .6th we ask from agricultural experts to answer existing pair comparisons matrix to determine local weights and overall weights.

.7 th I will recognize important strategies and then rate them based on priority

Data/Model Analysis .5 
Analytical Hierarchy process is one of the best designed systems for decision making with multiple criteria because these techniques can formulate problem as Hierarchy also it can use qualitative criteria and quantitative criteria in problem. These techniques can determine inconsistency index in decision. We did this method in several stages. In first stage we formed Hierarchy view of problem. In second stage we selected the important criteria. In third stage we calculate local weight and global weight. AHP method has different types of hierarchy. Special law isn't to hierarchy formation. Our hierarchy is includes goal, criteria and altematives. Goal is above of hierarchy. In this study goal is recognize important and Effective SWOT factor of agricultural development in city of Zanjan. SWOT factors are our altematives in this hierarchy then we have four types' altematives. Altematives are below of hierarchy. In this study our altematives is SWOT factors. We start to calculate after hierarchy formation. We .calculated local weights and overall weights. Show hierarchy model in figl

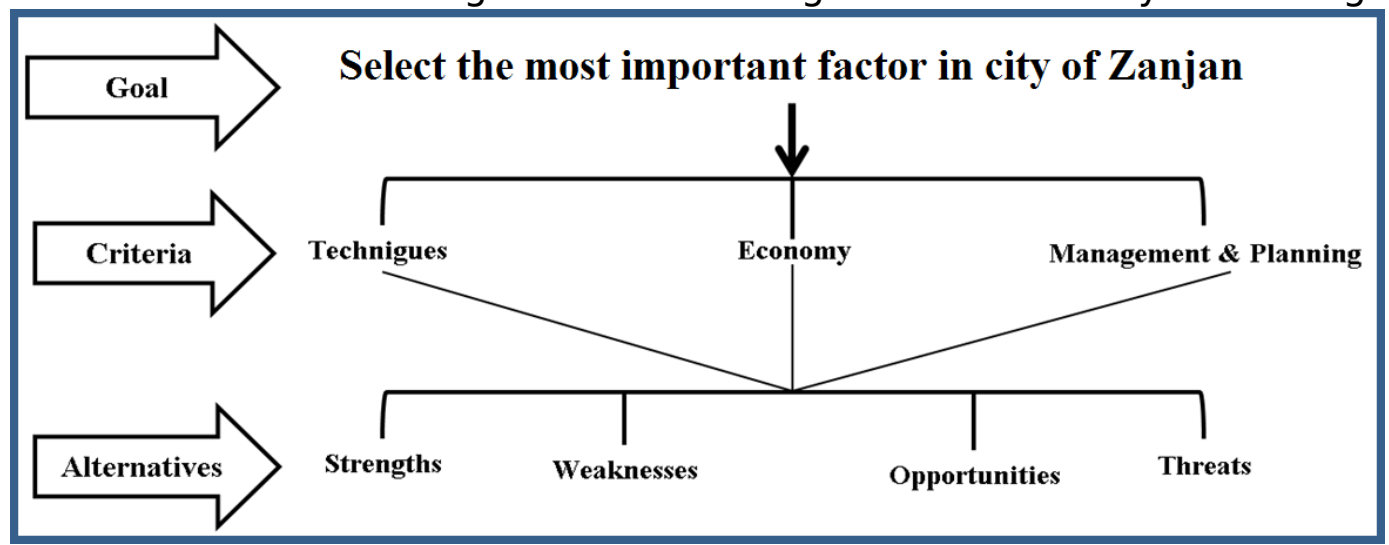

figl. Hierarchy model

Above general hierarchy is showing that we have five special hierarchies with :five different goals for each city. We show them in below .Hierarchy to select the most important strengths in the city of Zanjan .1 .Hierarchy to select the most important weaknesses in the city of Zanjan .2 .Hierarchy to select the most important opportunities in the city of Zanjan .3

.Hierarchy to select the most important threats in the city of Zanjan .4 Hierarchy to select the most important SWOT factors (it achieves when .5 .Compare internal and extemal factors with together) in the city of Zanjan The local weights calculate in three stages. First we formed pair comparisons matrix and then we get statistical community which help to fill and complete the matrixes. We will calculate geometric mean after completed the matrix by statistical community because we need a unit answers. We have one criteria matrix, four sub criteria matrixes and 12 altematives matrixes for this model so we have 17 matrixes in the overall. We have to complete all of the matrixes and then enter this data in to the Expert Choice software in addition we used participants table in this software for direct input of data. The second step is calculating inconsistently index. We calculate inconsistently index after completed pair comparison matrix. It is acceptable if inconsistently index is less than 0.10 but it is not when it is more than 0.10 so we have to change decision 
until inconsistently index be less than 0.10 . In this study we got inconsistently index by EC software. The third step is calculation of local weights and overall

.weights

In this study we have three criteria. We form pair comparisons matrix for criteria and then we ask agricultural experts to fill this pair comparisons matrix. In table1 showed geometric mean of answers Table1. Pair comparisons matrix for criteria Management and Techniqu Economi

Planning

$1 / 2$

$1 / 2$

1 es

2

1

2 cs

1

$1 / 2$

2
Economics

Techniques

Management and Planning

We calculate inconsistently index after complete pair comparisons matrix. Inconsistently index for pair comparisons matrix of factors is 0.05 so it is acceptable. We calculate local weights in this stage. In table 2 showed .local weight of criteria

Table2. Local weight of factors Local weight Criteria

0.311 Economics

0.196 Techniques

$0.493 \quad$ Management and

Planning

Above result showed Management and Planning is more important than another factors for agricultural .mechanization of city of Zanjan

sensitivity analysis 5.1

We used dynamic analysis and performance analysis for sensitivity analysis which showed in fig 2 , fig 3 


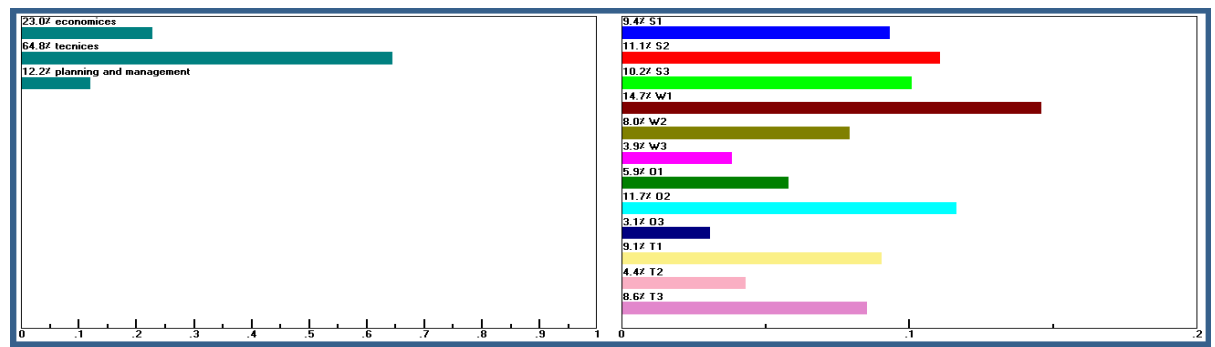

Fig2. Dynamic analysis

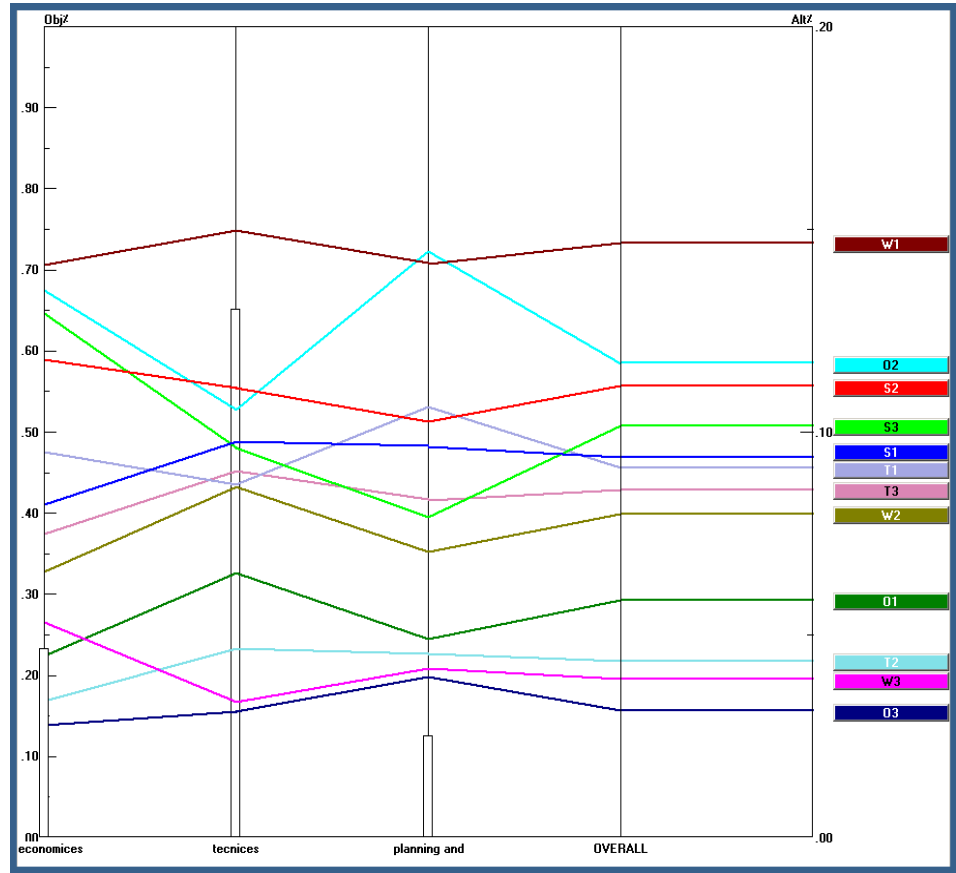

Fig3. Performance analysis

In the current situation Results of dynamic analysis showed that W1 is the most important factor but the value of criteria might be changed by implementation of the govemments new strategies in future, and thus rank of SWOT factors will change. Dynamic analysis showed in fig2. Results of performance analysis showed that $\mathrm{O} 3$ is In contrast with W1 because W1 is first regard to three criteria but $\mathrm{O} 3$ is a p p rox ima te $1 \mathrm{y}$ the last one. In addition performance analysis showed that results classified SWOT factors in 3 groups, first W1, 2nd includes 7 factors $(02, S 2, S 3, S 1, T 1, T 3, W 2)$, 3rd includes 4 .factors (01, T2, W3, 03). Performance analysis showed in fig3

strategy selection $\mathbf{5 . 2}$

Last stage of this study is selecting the important and suitable strategies for .implement in city of Zanjan to develop the agricultural mechanization in future

Limitations . 6 
:We feel these limitations

In the large and real model, number of Questions (pair comparisons) is very .1 much and this case has negative effect on the participants. So we have to find a .method for reduce the number of questions in pair comparisons

AHP and ANP methods are suitable tools for decisions making and strategy .2 selection in agriculture, agricultural development and agricultural mechanization, but it is not enough because it can't do system analysis when system is dynamic as well as static, so we have to find a method to combine these methods with

.system dynamics methods

Conclusions .7

We used SWOT-AHP method to evaluation of agricultural development in Zanjan province. Zanjan province has seven cities while each of the cities has different properties. This method has two main parts. First part is SWOT analysis. We got common properties in different cities by use SWOT analysis and then select three important cases for each of factors. Second part is AHP method. We have ranked the SWOT factors regard to three important criteria (Management and Planning, Economics and Techniques) by use AHP method. This method helps us to understanding agricultural development in city of Zanjan better. We showed value of SWOT factors by numeric value according to agricultural development. SWOT-AHP method is suitable method for .agricultural development researches

Reference. 8

Ali ahmadi, E., \& Fathollah, M., \& Tajeddin, I. (2003). A comprehensive approach to .1 .strategic management. Tolide danesh publication

Ghodsi pour, S. H. (2008). Analytic hierarchy process AHP. Polly techniques university 2 .publication

kurttila, M., \& pesonen, M., \& kangas, J., \& kajanus, M. (2000). Utilizing the analytic .3 hierarchy process (AHP) in SWOT analysis - a hybrid method and its application to a .forest-certification case. Forest policy and Economics, 1 (1), 41-52 Shrestha, PK., \& Alavalapati, JRR., \& Kalmbacher, RS. (2004). Exploring the potential .4 for silvopasture adoption in south-central Florida: an application of SWOT-AHP method.

.Agricultural systems, 81 (3), 185-199

yuksel, I., \& Dagdeviren, M. (2007). Using the analytical network process (ANP) in .5 SWOT analysis: a case study for a textile firm. Information sciences, 177 (16), 3364- 